\title{
Exploring English Language Needs of Indonesian Marine Pilots: A Need Analysis and Its Implications in ESP Classrooms
}

\author{
L.I. Sari \& R.H. Sari \\ Merchant Marine Polytechnic of Semarang, Semarang, Indonesia
}

\begin{abstract}
This study was aimed to investigate the English language needs of Indonesian Marine Pilots. Using a qualitative descriptive method of research, this study involved 14 Indonesian marine pilots and 2 Maritime English teachers. An open-ended questionnaire, interviews, and observations during a pilotage simulation were used to collect data. In addition to that, the result of the Marlins English Test for Seafarers was also used to support the data analysis. This study revealed that to conduct safe and effective pilotage services, the marine pilots need the following language skills: giving advice and giving order, asking and giving information (exchanging information), and using the Standard Marine Communication Phrases (SMCP). This study also showed that the marine pilots need improvements in their linguistic competence. They have problems in grammar or sentence structure, vocabulary, and pronunciation. Realizing their shortcomings, the Indonesian marine pilots want to improve their English competence, especially their speaking skills in conducting interpersonal conversations as well as transactional conversations. They also want to improve their writing skill. The findings indicate that in the teaching of Maritime English for marine pilots, it is important to provide learners with meaningful learning experience by using roleplays and simulations and address the communicative competence comprehensively.
\end{abstract}

\section{INTRODUCTION}

Pilotage is one of the ship operations that requires a great deal of communication and coordination between the marine pilot, the ship master, and other related crew. Pilotage refers to the activity of a marine pilot to get on board a ship to assist the ship to berth or unberth [1]. It involves the activity of navigating all kinds of ships safely through domestic waterways while ensuring the safety of the environment, people, and cargo [2]. Marine pilots are professional seafarers who collaborate with the vessel's crew to give navigational advice to captains [3], [4]. As a 'newcomer' on the ship's bridge, they have to understand how the bridge team works together and how the team has communication with each other [5].
Their role, no doubt, is highly important. Marine pilots have a crucial role as local guides with extensive knowledge of the waters for which they are certified [6]. Thus, they must be familiar with every aspect of the pilotage district for which they are licensed and therefore must be able to recount under all weather and visibility conditions - every channel twist, bridge, and navigational aid.

There are several important responsibilities of marine pilots according to the EU [2] including navigation control; checking the status of the switching of each vessel; reporting of shortcomings and deficiencies; having coordination with the towing and mooring services of the port; reporting any incidents detected in navigation in port waters to the 
maritime and port authority; reporting any pollution sources found in port waters; reporting on the failure or breakdown of beacon signals from the port and its vicinity; and conducting communication with authorities in case of maritime emergencies.

Marine Pilots have a very close relationship with the ship master. They give guidance to the ship master related to the berthing and unberthing activities of the ship [7]. Therefore, they must build and maintain good communication [8]. It is said that the master's knowledge is often vessel-specific, while the marine pilot's knowledge is waterway-specific [9]. Even though the Master is an expert in navigating vessels, he might not familiar with the specific environment of ports. Thus, he needs help from the Pilot in navigating his vessel to ensure that the vessel, crew, passengers, and cargo arrive at their next port of call safely and efficiently. The relationship is based on trust, honesty, and assurance. The master should be honest in describing the condition of his ship, while the pilot should be truthful in describing possible problems, routes, tugs, line handlers and shore facilities, and the local regulations. In addition to that, the pilot must assure the Master that he/she is competent and capable of handling the ship. The Pilot also should consult with the Master if there are doubts related to the ship's manoeuvring [2].

However, maritime communications sometimes cannot run the way they are planned. Misunderstandings that led to accidents were found to be many. It is said that $80 \%$ of maritime accidents are because of human error of which one-third of it is related to communication failure [10]. Human error also contributes to the major cause of the collision and grounding accidents in which mostly occur in narrow channels and during berthing/unberthing manoeuvres [11], [12]. The importance of the human element in contributing to the safe operation of a vessel is crystal clear, in which the communication skills are very crucial [13], [14].

Low language ability has become one of the barriers to achieve accurate and understandable communication among crew of different nationalities. A Ship Master revealed an uncomfortable situation he ever experienced when two pilots on his vessel often switched to French between themselves instead of speaking English. He also experienced that his helm orders had to be translated into three different languages before they were executed by the helmsman. Another communication breakdown during Pilotage happened when the Pilot used a language that could not be understood by the Master when communicating with the tugs. This can reduce the Master's awareness of the situation that is happening on the vessel [8].

Due to the important role of marine pilots, various studies have been conducted by various scholars. Many of them discuss the physical and psychological aspects of pilots. Among the studies are: sleep disruption and the decline of cognitive function of marine pilots [15], pilot's alertness and psychomotor performance levels [16], fatigue and coping strategies [17], pilots' health and well-being [18], pilot's psychophysical stress and strain [19], [20], pilot's mental workload and physiological reactions [21], pilots' job satisfaction and turnover [22]. However, the studies that discuss pilots' language aspects are still limited. In Indonesia, where English is considered as a foreign language, the language issue in maritime operations becomes crucial. Many efforts have been conducted by maritime education and training institutions to provide English programs and to improve the English competency of seafarers. However, in some cases, the results are still not satisfactory.

In doing their duties, marine pilots need to build and maintain good communication and trust with the ship masters and other related crew. Having good English will help them provide the best pilotage services. This study attempts to fill the gap in the studies related to marine pilots by investigating their English language needs. It is conducted in the Indonesian context and uses Hutchinson and Waters' need analysis framework [23].

Brown described need analysis as the systematic collection and analysis of all subjective and objective information necessary to define and validate defensible curriculum purposes that satisfy the language learning necessities of students within the context of particular institutions that influence the learning and teaching situation [24]. Macalister and Nation [23] argued that need analysis is important to make sure that a certain course contains relevant and useful things to learn for the students. Data obtained from need analysis can become a valuable resource to improve ESP teaching. They quoted three types of needs proposed by Hutchinson and Waters.

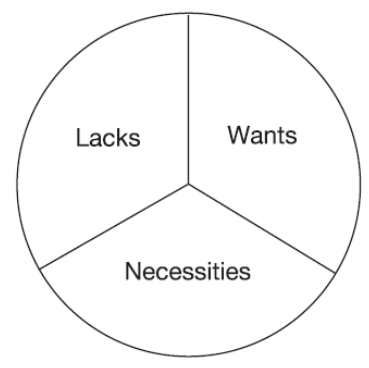

Figure 1. Three types of needs

"Necessities" refers to the questions: what is necessary in the learners' use of language? Necessities reflect the demands of the students' target tasks. For example, "what will they have to do in their working places?". "Lacks" refers to the question: "What do the learners lack?". This involves looking at where learners are at present, how good they are in performing their jobs. "Wants" refers to the question: "What do the learners wish to learn?". This involves learners' views about what they think is useful for them.

Three research questions guide this study, namely: 1 What English language competencies are required by Indonesian Marine Pilots to conduct safe and effective pilotage services?

2 What are the shortcomings of Indonesian Marine Pilots in terms of the English language?

3 What language skills do the Indonesian Marine Pilots wish to improve?

It is expected that the result of this study can give significant contributions to the field of Maritime Education and Training. This study can be one of the 
valuable references to improve the syllabus and teaching materials of the ESP course for Marine Pilots, especially in the Indonesian context where English is considered as a foreign language.

\section{METHODOLOGY}

\subsection{Participant of the Study}

The participants involved in this study were 14 male Indonesian marine pilots who joined a Maritime English Course in a Maritime Polytechnic. Their age ranged from 34 - 54 years old. The average age is 42 years old. Their experience of becoming marine pilots ranged from 5 - 15 years. The average pilotage service is 10 years. The detail of the participants' characteristics can be seen in Table 1 .

Table 1. The Characteristics of the Participants

\begin{tabular}{lll}
\hline Pilot & \multicolumn{2}{l}{$\begin{array}{l}\text { Age } \\
\text { (years old) }\end{array}$} \\
\hline Pilot 1 & 45 & 15 years \\
Pilot 2 & 44 & 11 years \\
Pilot 3 & 35 & 5 years \\
Pilot 4 & 34 & 9 years \\
Pilot 5 & 42 & 8 years \\
Pilot 6 & 45 & 13 years \\
Pilot 7 & 43 & 6 years \\
Pilot 8 & 40 & 12 years \\
Pilot 9 & 45 & 10 years \\
Pilot 10 & 41 & 10 years \\
Pilot 11 & 44 & 15 years \\
Pilot 12 & 54 & 15 years \\
Pilot 13 & 42 & 10 years \\
Pilot 14 & 45 & 10 years \\
Average & 42 & 10 years \\
\hline
\end{tabular}

All of the participants were previously seafarers before they worked as marine pilots. The long period of working in the maritime field indicates that they have considerable knowledge and experience in navigation and pilotage.

To obtain additional information, two English teachers involved during the course were interviewed.

\subsection{Data Collection}

\subsubsection{Methods}

There were several methods of data collection used in this study. An open-ended questionnaire was used to collect information about the necessities, the shortcomings, and the wants of marine pilots related to their English language ability. A Semi-structured interview was conducted with the participants to clarify information obtained from the questionnaire. In addition to that, an interview with the teachers was used to get more comprehensive information about the present language ability of the participants. The observation was conducted during the pilotage simulation to obtain information about the participants' present language ability. Regulation related to Pilotage in Indonesia was examined to obtain information about the duties and the responsibilities of marine pilots. The result of the Marlins English Test for Seafarers was used to find out the maritime English level of the pilots and to identify language aspects that need improvements.

\subsubsection{Procedure}

Data were collected when the participants joined a Maritime English course in a Maritime Polytechnic. The course was conducted in one week. On the first day of the course, after the class session finished, the researchers explained the research to the participants. On the second day of the course, the researchers distributed the questionnaire to the participants. On the next day, an interview was conducted with the participants to clarify their answers to the questionnaire and to elicit more detailed information. The interview was held during the break after the class sessions and it was completed in 3 days.

The participants were given eight questions related to their jobs as marine pilots and the English communication that they conducted. The questions were as follows:

1 What are your daily duties and responsibilities?

2 How do you conduct your duties?

3 Do your duties involve communication with other people? How do you conduct communication?

4 Do you use English for communication at work? How often do you use English?

5 What duties require English competence?

6 What difficulties do you face during working? (especially which are related to English communication)

7 What English competencies do you want to improve?

8 What English materials do you wish to learn?

Pilotage simulation was held as one of the sessions of the course. During the pilotage simulation, an observation was conducted by the researchers. The pilotage simulation was held in the Ship Handling Simulator. There were 2 cubicles used during the simulation. The conversations in each cubicle were recorded. However, due to the limitation of the recorder, there were only five recordings available. The Marlins English test was administered on the last day of the course. Before taking the test, short familiarization about the test was given to the participants.

Interview with the teachers was conducted after the course finished. The teachers' perception of the present language ability of marine pilots was explored.

\subsection{Data analysis}

This research employed a qualitative descriptive method, in which the researchers became the main instrument of data analysis. Data analysis was started with compiling all data obtained from the questionnaire, interview (both with the participants and the teachers), recordings of the simulation, regulation related to marine pilot in Indonesia, and the Marlins English Test for Seafarers.

The questionnaires were recapitulated and the interviews with the participants were transcribed. 
The data were then rearranged into categories based on questions on the questionnaire and presented in combination with the interview result using tables.

The recordings of the pilotage simulation were transcribed and analyzed to find errors in communication.

The teachers' interview was also transcribed to find supporting information about the present ability of the participants. The result of the Marlins Test was recapped and broken down into the categories of listening, grammar, vocabulary, time and numbers, pronunciation, and reading. The data were then reorganized using a table.

All of the data were then analyzed and interpreted with the guide of the research questions.

\section{RESULTS AND DISCUSSION}

\subsection{English language competencies which are required by Indonesian Marine Pilots to conduct safe and effective pilotage service.}

To answer research question 1, there were several data used. Firstly, the Decree of the Ministry of Transportation Number 57 the Year 2015 concerning Pilotage. Secondly, the result of the questionnaire and the interview with the participants. From the result of data analysis, the language competencies that are required by Indonesian Marine Pilots to conduct safe and effective pilotage service are:

1 Giving advice and giving order

According to the Decree of the Ministry of Transportation Number 57 the Year 2015, marine pilots have to advise the ship master regarding the pilotage process. In conducting pilotage duties, the participants often have to use the English language, moreover when they assist or escort foreign vessels and meet foreign ship masters. Since the incident of MV. Soul of Luck which hit the container crane at the Port of Tanjung Emas, all Indonesian pilots have been encouraged to use English, even though they assist local vessels. Sometimes, pilots are also asked by the Ship Master to handle the ship's manoeuvring. In this situation, pilots take over the command under the Master's supervision. Therefore, they must be able to give a clear and accurate command to avoid error and misunderstanding.

2 Asking and giving information (exchanging information)

Marine pilots have to ask for information from the ship master related to the ship's characteristics. They also have to give information to the master related to the port's characteristics. The skills of asking and giving information are important to make the communication run well.

Giving information can be in the form of reporting which becomes one of the language competencies that is needed by the marine pilots. According to the Decree of the Ministry of Transportation Number 57 the Year 2015 regarding Pilotage, pilots have to report accidents immediately to the Port Authority. Pilots also have to report other issues such as changing of depth in the fairway, the position of the fishing gears or other barriers that endanger navigation, and the position of buoys. Pilots give information to the master related to berthing / unberthing activity, including information about the port characteristic, the weather condition, the current, the number of assist tugs, loading and unloading activity, etc.

Besides giving information related to pilotage, pilots sometimes also act as a "tour guide" who give information about interesting places near the Port to the Ship's Master, Crew, or passengers of cruise ships. Pilots also need to have a small talk or a friendly talk with the Master to build trust and chemistry. This is revealed by Pilot 4 during the interview who said that it is important for a pilot and a captain to build good communication in a relatively short time. Supporting the statement of Pilot 4, Pilot 10 admitted that having good English can help him to be more confident when talking with the Master and to gain the Master's trust concerning his competency as a marine pilot.

3 Standard Marine Communication Phrase (SMCP) In addition to having good knowledge of the English language, it is also mandatory for marine pilots to know about the IMO Standard Marine Communication Phrase (SMCP). In 1997, IMO has published SMCP as guidance for navigational and safety communication from ship to shore and vice versa, ship to ship, and onboard ships. Maritime communication is made to be precise, simple, and unambiguous to avoid confusion and error. Due to the increased number of international merchant vessels in which the crews speak many different languages, problems of communication may cause misunderstanding that can lead to dangers. Several pilots who participated in this research admitted that they have difficulty when they meet ship masters who talk too fast or who have a very different accent. The consistent use of SMCP for communication can reduce the risks of misunderstanding and other communication problems.

\subsection{The shortcomings of the Indonesian Marine Pilots in terms of English language.}

To answer research question number 2, there are several data used. Firstly, the result of the questionnaire and interview with the participants, secondly the result of the interview with the English teachers, thirdly the result of pilotage simulation, and fourth the result of the Marlins English Test.

The findings showed that the marine pilots need to improve the following aspects.

\subsubsection{Grammar or sentence structure}

Most of the participants agreed if they have limited English grammar. They know the theory, but they find difficulties to use it in communication. The English teachers also revealed that the participants have problems in accuracy. They rarely use correct grammar when having communication or when doing assignments in the classroom.

Lack of accuracy can cause problems when the marine pilots have to conduct communication with 
people who have English as the mother tongue. As Pilot 6 explained during the interview:

"When having communication with the ship masters, especially those from Europe, grammar plays a very important role. For example, when I say "the vessel sink yesterday". He became confused. "Sink?" "Oh, ya sank". But when I have a conversation with Asian people, I don't find any significant problems".

The result of the Marlins English Test also revealed that the participants have a low score for the grammar section. Only 14\% of the participants scored more than 70 . The average score for the grammar section was 58. The grammar section of the Marlins Test examines the test takers' knowledge about English grammar or the accuracy of sentence structure. The overall recapitulation of the Marlins Test can be seen in Table 2 .

Problems with sentence structure can also be seen from the pilotage simulation. Mostly, the problems occurred in the verb formation and when asking questions. Here are several examples of errors in verb formation:

- "can I starting now, or waiting for the Cartefour?" (recording 1).

- "Pilot station, this is MV. Terrathree we will departure from Semarang port using 2 tugs (recording 5).

- The participants also had difficulties when constructing interrogative sentences. Here are several examples of errors in making questions:

- "What...any one vessel in buoy number 1?" (recording 2)

- "Ok... maybe any information, any tug for the assist my ship? Over." (recording 3)

- "How many minutes the tugs trouble, Sir?" (recording 4)

The excerpts of the pilotage simulation show that the participants made several errors during communication. However, the errors didn't cause a communication breakdown. All of the parties still could understand each other. It was probably because all of the people involved in the communication were Indonesian.

\subsubsection{Vocabulary or word choice}

Most of the participants admitted that they have a limited vocabulary, especially when they have to do casual conversation or friendly talk with the Master, the crew, or the passengers of a vessel. For technical vocabulary that is related to their daily jobs and duties, they didn't find any significant problems.

The result of the Marlins Test which assessed the participants' knowledge in Maritime vocabulary showed that most of the participants have a good maritime vocabulary. The average score for the vocabulary aspect was 80 , in which $78 \%$ of the participants scored more than 70. Supporting the finding, the English teachers added that the participants have no significant problem when using the technical terminologies during working. It is probably because they use the vocabulary every day.

However, when it comes to casual conversation, they have difficulties finding the proper vocabulary. Lack of vocabulary to engage in casual conversation makes the participants avoid having a long conversation with the ship master or with the crew. They focus on doing communication related to pilotage services.

Related to the use of SMCP during pilotage simulation, there are several errors found. Firstly, the absence of message markers and secondly, in correcting the message that has been transmitted before. Message markers are used to facilitate maritime communication, especially when someone has to do VHF communication. The consistent use of message markers is expected to reduce the possibility of misunderstanding. However, during the pilotage simulation, the use of SMCP message markers was not found.

IMO has given guidance in SMCP related to how to correct a mistake in a message. The use of the word "mistake" followed by the word: "correction..." plus the corrected part of the message has been explained in SMCP. However, when making mistake in saying a message, the participants didn't use the terminologies. Here are several examples found in the simulation:

Table 2. The recapitulation of the Marlins English Test Result

\begin{tabular}{|c|c|c|c|c|c|c|c|}
\hline Pilot & Listening & Grammar & Vocabulary & Time and Numbers & Pronunciation & Reading & Overall score \\
\hline Pilot 1 & 56 & 57 & 89 & 100 & 56 & 50 & 70 \\
\hline Pilot 2 & 76 & 67 & 87 & 80 & 67 & 83 & 78 \\
\hline Pilot 3 & 88 & 63 & 98 & 100 & 78 & 83 & 85 \\
\hline Pilot 4 & 92 & 83 & 98 & 100 & 67 & 50 & 88 \\
\hline Pilot 5 & 48 & 43 & 69 & 100 & 78 & 33 & 58 \\
\hline Pilot 6 & 52 & 60 & 78 & 80 & 56 & 17 & 63 \\
\hline Pilot 7 & 76 & 67 & 76 & 100 & 67 & 33 & 72 \\
\hline Pilot 8 & 96 & 77 & 87 & 80 & 67 & 50 & 83 \\
\hline Pilot 9 & 72 & 40 & 69 & 80 & 44 & 33 & 59 \\
\hline Pilot 10 & 68 & 57 & 76 & 100 & 44 & 50 & 67 \\
\hline Pilot 11 & 72 & 37 & 73 & 80 & 56 & 33 & 61 \\
\hline Pilot 12 & 68 & 37 & 78 & 100 & 44 & 0 & 60 \\
\hline Pilot 13 & 68 & 67 & 67 & 80 & 89 & 67 & 69 \\
\hline Pilot 14 & 68 & 53 & 76 & 100 & 67 & 33 & 67 \\
\hline Mean & 71 & 58 & 80 & 91 & 63 & 44 & 70 \\
\hline
\end{tabular}


- "Semarang pilot, Cartefour. My position passing buoy number 2, eh number 3 over" (recording 1)

- "Yes, now slow ahead sir. Speed increase from two... three point six to three point seven" (recording 2)

However, the errors didn't cause any breakdown during the communication. Again, it was probably because all of the parties involved in communication are Indonesian.

The percentage of errors in grammar and vocabulary of the pilotage simulation activity is shown in Figure 2. From the diagram, it can be seen that $45 \%$ of errors are not using SMCP appropriately. $25 \%$ of errors are related to sentence construction in which the participants made some errors in constructing interrogatives sentences. 20\% of errors are related to verb formation. For example, instead of using the verb "depart", the participants use the word "departure" in their sentences. $10 \%$ of errors are related to the word choice.

\section{- $\mathrm{SMCP}$ sentence construction $\quad$ verb formation word choice}

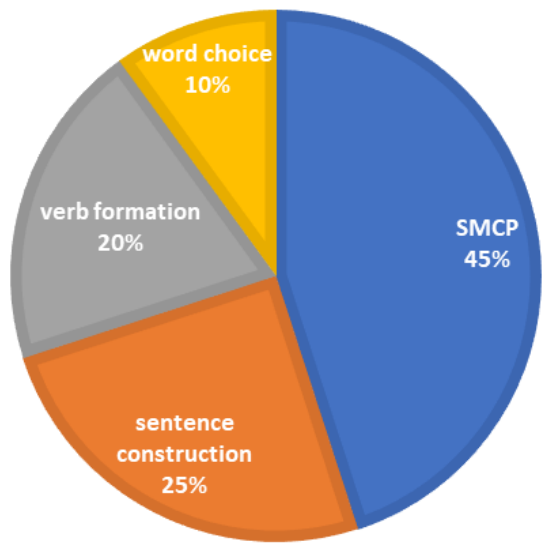

Figure 2. The percentage of errors in grammar and vocabulary during the pilotage simulation

\subsubsection{Pronunciation}

Most of the participants admitted that they have problems with pronunciation. The English teachers also reported that the participants showed less accuracy in pronunciation. The result of the Marlins Test revealed a similar finding that only $21 \%$ of the participants scored more than 70 . The average score for the pronunciation section was 63 .

Here are examples of interview excerpts concerning the participants' difficulty in pronunciation:

- "I think I have problems with pronunciation. Sometimes I cannot understand other people's utterances. Sometimes other people cannot understand my utterance" (Pilot 3).

- "I find difficulties in communication especially when I meet Captain from China. The accent is very difficult to be understood" (Pilot 5)

- "I found difficulties when I met crew or captain from Europe. They usually talk very fast. But I'm glad they can understand me" (Pilot 7)

- "The problem is pronunciation. The crew from different countries have different pronunciations. Sometimes it makes me confused. To overcome this problem, sometimes I use body language to help me express what I want to say" (Pilot 9)

The excerpts of the interview showed that the participants realized that they have problems in pronunciation. When people talk too fast, it was difficult for the participants to catch the meaning, moreover when they were not familiar with the accents. British, Indian, Russian, and Chinese accents were considered "difficult" to be understood. To overcome this problem, usually, the participants use gestures to help them express what they want to say.

\subsection{Skills that the Indonesian Marine Pilots wish to improve in terms of the English language.}

To answer research question 3 , the result of the questionnaire and interview are used. Research question 3 attempts to reveal the participants' expectations about the language competence that they want to improve and the materials that they want to learn. There are two skills that become the concern of the participants: speaking and writing.

\subsubsection{Speaking skills in casual conversation or interpersonal conversation.}

Speaking can have a transactional or interactional purpose. Interactional purpose refers to the interaction that serves primarily for a social function in which the individuals engage in a social situation and build comfortable feeling in the interaction. As Richards said that "When people meet, they exchange greetings, engage in small talk, recount recent experiences, and so on" [25].

As explained in the previous section, one of the Pilots' duties is sometimes they have to act as a tour guide for the ship's master, crew, or passengers who ask them about interesting places or good restaurants in the town to visit. Pilots also need to build trust and chemistry with the Ship Master by having a friendly conversation. One of the pilots said that having good English can help him to gain the Master's trust that he is capable of doing his job as a Pilot. That is evidence that the English language plays a very important role to bridge communication across different nationalities.

Due to the awareness that speaking skill is important, most of the participants then want to improve their skills in having a casual or friendly conversation with foreign people they meet during working as a pilot, for example, the ship's master, the ship's crew or passengers of cruise ships. As Pilot 7 explained that he wanted to have more conversation with the Captain, but due to limited speaking ability he could not do it.

"I found difficulties when I met the crew or captain from Europe. They usually talk very fast. But I'm glad they can understand me. Perhaps it's because we just talk about pilotage activity. We do not talk about any other things. I actually want to talk more and explain about good places or restaurants to visit near the Port, but I can't because I don't know how to say it in English" 
The excerpt indicates that the participants do not only need skills in conducting transactional conversation as a Marine Pilot, but also casual or interpersonal conversation. They want to improve their skills to engage in more friendly conversations with foreign people using English. This indicates that in ESP teaching, besides the technical genre, the nontechnical genre also needs to be addressed. This is in line with the studies conducted by [26] and [27].

\subsubsection{Speaking skill in transactional conversation}

In transactional conversation, the message becomes the most important aspect. "Talk as transaction refers to situations where the focus is on what is said or done. The message and making oneself understood clearly and accurately is the central focus, rather than the participants" [25]. The transactional conversation is more predictable and easier to plan than interpersonal conversation.

In conducting their duties, Pilots have had guidance about how to conduct communication in a standard way. They have the Standard Marine Communication Phrase (SMCP) as guidance. However, based on the pilotage simulation the SMCP was not used consistently by the participants to facilitate their communication. Some of the participants realized this situation and wish to have more learning and practice of using SMCP for pilotage.

Accuracy becomes the concern of the participants, especially during their speaking. Sometimes they are not sure about the pronunciation when having communication. They also have a limited vocabulary and grammar. Therefore, they want to improve their vocabulary, pronunciation, and grammar to be more fluent in communication.

\subsubsection{Writing skill}

Writing belongs to productive skills in which individuals compose a written text about certain topics. Unlike spoken text which is unplanned and less structured, written text is planned and more organized. Written text tends to use a longer and more complex sentence, and also has higher lexical density. Therefore, grammar plays a very important role. Writing a report is not the thing that the participants have to do every day. They only do the duty occasionally, for example when there is an incident that happens. However, when they have to write, they found difficulty in writing correctly. Usually, the problem is related to sentence structure, tense, and vocabulary. Therefore, the participants want to improve their ability in constructing sentences appropriately. In maritime education and training in Indonesia, seafarers' writing skill tends to receive less attention than the other language skills. A study conducted in China showed a similar finding that the importance of writing was underestimated in the Maritime English education and training in China [28].

\section{PEDAGOGICAL IMPLICATIONS}

This study has several pedagogical implications. Firstly, the teaching and practicing of communication using the Standard Marine Communication Phrases (SMCP) through roleplays and simulations should be conducted more frequently and consistently. Roleplays and simulations will enable the participants to experience almost-realcommunications of Pilotage and provide them with meaningful activities of learning. For adult language learners, relevant and meaningful activities are highly significant to boost learning motivation which can improve the effectiveness of learning [29]. Roleplays and simulations also provide opportunities for the participants to have interaction with their peers and to receive feedbacks which bring a good influence on their language learning [30]. The use of roleplays and simulations belongs to the so-called "contextualized language teaching" which represents the "realworld" tasks and has been proved to improve students' performance in the language classroom [31]. The consistent use of SMCP as the standardized language for maritime operations will be beneficial when the participants have to deal with a multilingual and multicultural crew of ships [32].

Secondly, the linguistic competence of seafarers needs to be improved, especially for pronunciation and intonation. Maritime communication often involves spoken communication, in which the accuracy of speaking will highly influence the reception of the listeners. Moreover, if the interlocutors come from a different country and thus, have different accents. In several cases, the marine pilots have difficulties in understanding the ship masters' talks due to unfamiliar accents and inaccurate pronunciation. The marine pilots also admitted that they need to improve their pronunciation.

Thirdly, the teaching and learning of Maritime English for Pilots should not only focus on transactional or technical communication but also include interpersonal communication and address socio-cultural competence. In ESP, linguistic competence alone will not be enough for learners to be able to perform their duties effectively at the workplace. During the duty of Pilotage, marine pilots meet ship's masters and crew from various nationalities. Good interpersonal communication and socio-cultural competence will help the pilots to build trust and chemistry with the ship's master. They will also support the pilots to conduct a casual or friendly conversation with the ship's crew or cruise ship's passengers. In addition to that, the socio-cultural competence will prevent communication breakdown during Pilotage which is caused by cultural differences between the pilots, the ship's master, and other related crew. Thus, integration of socio-cultural competence into the teaching and learning activities in the classroom is very important [33]-[35].

\section{CONCLUSION}

Marine Pilots have specific language needs due to their specific duties. This study, which was aimed to 
investigate the English language needs of Indonesian Marine Pilots who joined a Maritime English course in one of the maritime polytechnics revealed several findings.

To conduct safe and effective pilotage services, the marine pilots need the following skill: giving advice and giving order, asking and giving information (exchanging information), and using the Standard Marine Communication Phrases (SMCP). This study also revealed that marine pilots need to improve their linguistic competence. They have problems in grammar or sentence structure, vocabulary or word choice, and pronunciation. Realizing their shortcomings, the Indonesian marine pilots want to improve their English skills, especially their speaking skills in conducting interpersonal conversation as well as transactional conversation using SMCP. They also want to improve their writing skill. The findings indicate that in the teaching of Maritime English for marine pilots, it is important to address the communicative competence comprehensively. It means that all of the competencies including linguistic competence, socio-cultural competence, interactional competence, formulaic competence, strategic competence, and discourse competence should be integrated into the teaching and learning activity. The use of roleplays and simulations can also provide learners with meaningful experiences and thus, can make the teaching and learning activities more effective.

However, there are some limitations in this research due to the small number of marine pilots who were involved in this research. Nevertheless, the findings of this study may be relevant to the condition of other Asian marine pilots where English is considered as a foreign language in their countries. A larger scope of study is needed to obtain more comprehensive insights.

\section{ACKNOWLEDGEMENTS}

The authors would like to extend the greatest appreciation to all marine pilots who have been willing to be involved in this study as participants. We would also like to thank our colleagues: Capt. Samsul Huda, Andarini Handayani, and Pratama Irwin Talenta who have helped us during the interview and pilotage simulation. Last but not least, thanks to our assistants: Nuki Dhamayanti and Daniel Masae who have given a remarkable contribution to this research.

\section{REFERENCES}

[1] Y. A. Park, T. L. Yip, and H. G. Park, "An analysis of pilotage marine accidents in Korea," Asian J. Shipp. Logist., vol. 35, no. 1, pp. 49-54, 2019.

[2] S. N. Kalulu, "An analysis of the maritime pilot training and certification: a comparative study between Denmark and Namibia," World Maritime University, 2018.

[3] J. Kuronen and U. Tapaninen, "Evaluation of maritime safety policy instruments," WMU J. Marit. Aff., vol. 9, pp. 45-61, 2010.

[4] J. Lappalainen, V. Kunnaala, and U. Tapaninen, "Present pilotage practices in Finland," WMU J. Marit. Aff., vol. 13, pp. 77-99, 2014.
[5] G. K. Özbağ and G. Ç. Ceyhun, “Does job satisfaction mediate the relationship between work-family conflict and turnover? A study of Turkish marine pilots," Procedia - Soc. Behav. Sci., vol. 140, pp. 643-649, 2014.

[6] M. Hontvedt, "Professional vision in simulated environments - Examining professional maritime pilots' performance of work tasks in a full-mission ship simulator," Learn. Cult. Soc. Interact., vol. 7, pp. 71-84, 2015.

[7] J. T. Mansson, M. Lutzhoft, and B. Brooks, "Joint activity in the maritime traffic system: Perceptions of ship masters, maritime pilots, tug masters, and Vessel Traffic Service operators," J. Navig., vol. 70, no. 3, pp. 547-560, 2017.

[8] A. Čulić-Viskota, "Essential English for pilotage and tug assistance - Proposal for SMCP extension," Trans. Marit. Sci., vol. 3, no. 2, pp. 158-164, 2014.

[9] A. Carse, "The feel of 13,000 containers: How pilots learn to navigate changing logistical environments," Ethnos, pp. 1-24, 2019.

[10] R. Ahmmed, "The difficulties of maritime communication and the roles of English teachers," Bangladesh Marit. J., vol. 1, no. 1, pp. 26-34, 2018.

[11] Ö. Uğurlu, M. Kaptan, S. Kum, and S. Yildiz, "Pilotage services in Turkey; key issues and ideal pilotage," J. Mar. Eng. Technol., vol. 16, no. 2, pp. 51-60, 2017.

[12] Y. Xi, S. Fu, S. Hu, T. Qin, and Z. Yang, "The moderating effect of risk tolerance on the hazardous attitudes and safety behavior of maritime pilots: A Chinese case," in ICTIS 2019 - 5th International Conference on Transportation Information and Safety, 2019, pp. 286-292.

[13] A. A. Atiyah, C. Kontovas, F. Saeed, and Z. Yang, "Marine pilot's reliability index (MPRI): Evaluation of marine pilot reliability in uncertain environments," in ICTIS 2019 - 5th International Conference on Transportation Information and Safety, 2019, pp. 558564.

[14] W. K. K. Hsu, "Assessing the safety factors of ship berthing operations," J. Navig., vol. 68, no. 3, pp. 576$588,2015$.

[15] J. Thomas, S. Overeem, M. Dresler, R. P. C. Kessels, and J. A. H. R. Claassen, "Shift-work-related sleep disruption and the risk of decline in cognitive function: The CRUISE Study," J. Sleep Res., no. April, pp. 1-9, 2020.

[16] P. Boudreau, S. Lafrance, and D. B. Boivin, “Alertness and psychomotor performance levels of marine pilots on an irregular work roster," Chronobiol. Int., vol. 35, no. 6, pp. 773-784, 2018.

[17] T. P. Chambers and L. C. Main, "Symptoms of fatigue and coping strategies in maritime pilotage," Int. Marit. Health, vol. 66, no. 1, pp. 43-48, 2015.

[18] L. C. Main and T. P. Chambers, "Factors affecting maritime pilots' health and well-being: a systematic review," Int. Marit. Health, vol. 66, no. 4, pp. 220-232, 2015.

[19] F. Barbarewicz, H. J. Jensen, V. Harth, and M. Oldenburg, "Psychophysical stress and strain of maritime pilots in Germany. A cross-sectional study," PLoS One, vol. 14, no. 8, pp. 1-12, 2019.

[20] L. C. Main, A. Wolkow, and T. P. Chambers, "Quantifying the physiological stress response to simulated maritime pilotage tasks," J. Occup. Environ. Med., vol. 59, no. 11, pp. 1078-1083, 2017.

[21] L. Orlandi and B. Brooks, "Measuring mental workload and physiological reactions in marine pilots: Building bridges towards redlines of performance," Appl. Ergon., vol. 69, pp. 74-92, 2018.

[22] G. C. Ceyhun and G. K. Ozbag, “Does burnout working conditions affect marine pilots' job satisfaction and turnover intentions? A study of Turkish marine pilots," Int. J. Acad. Res. Bus. Soc. Sci., vol. 4, no. 3, pp. 301-312, 2014. 
[23] J. Macalister and I. S. P. Nation, Language Curriculum Design. Routledge, 2010.

[24] M. Aliakbari and M. Boghayeri, "A need analysis approach to ESP design in Iranian context," Procedia Soc. Behav. Sci., vol. 98, pp. 175-181, 2014.

[25] W. M. Julio and O. R. Contreras, "Transactional communication strategies to influence pre-service teachers' speaking skill," GiST Educ. Learn. Res. J., vol. 16, no. 16, pp. 33-55, 2018.

[26] C. S. C. Chan, “Long-term workplace communication needs of business professionals: Stories from Hong Kong senior executives and their implications for ESP and higher education," English Specif. Purp., vol. 56, pp. 68-83, 2019.

[27] A. Alfehaid and N. Alkhatib, "ESP: A real-life perspective," Asian ESP J., vol. 16, no. 2.1, pp. 159-175, 2020.

[28] L. Fan, "An overview of Chinese seafarers' communicative competence in English-Chinese seafarers' perspectives," TransNav, Int. J. Mar. Navig. Saf. Sea Transp., vol. 11, no. 4, pp. 577-581, 2017.

[29] D. Severinsen, L. Kennedy, and S. Mohamud, "Teaching strategies that motivate English language adult literacy learners to invest in their education: A literature review," Lit. Numer. Stud., vol. 26, no. 1, pp. 25-42, 2018.

[30] B. Ozfidan, K. L. Machtmes, and H. Demir, "Sociocultural factors in second language learning: A case study of adventurous adult language learners," Eur. J. Educ. Res., vol. 3, no. 4, pp. 185-191, 2014.

[31] R. S. Medriano and A. S. Bautista, "Integrating business English communication in the contextualized teaching of an ESL graduate course," Asian ESP J., vol. 16, no. 2.1, pp. 70-88, 2020.

[32] A. Bocanegra Valle, "The language of seafaring: Standardized conventions and discursive features in speech communications," Int. J. English Stud., vol. 11, no. 1, p. 35, 2011.

[33] I. O. Guryanov, A. E. Rakhimova, and M. C. Guzman, "Socio-cultural competence in teaching foreign languages," Int. J. High. Educ., vol. 8, no. 7, pp. 116-120, 2019.

[34] M. S. Safina, "Formation of socio-cultural competence in foreign language teaching," Procedia - Soc. Behav. Sci., vol. 136, pp. 80-83, 2014.

[35] I. Anužienè, "The structure of socio-cultural competence (self) development," Vocat. Train. Res. Realities, vol. 26, no. 1, 2015. 